\title{
Morphology of polymer networks formed in the chiral and non chiral phases of an anti-ferroelectric liquid crystal
}

Article

Accepted Version

Singh, U., Spink, M., Davis, F. and Mitchell, G. (2015)

Morphology of polymer networks formed in the chiral and non chiral phases of an anti-ferroelectric liquid crystal. Chemical Physics Letters, 641. pp. 80-83. ISSN 0009-2614 doi: https://doi.org/10.1016/j.cplett.2015.10.047 Available at https://centaur.reading.ac.uk/46515/

It is advisable to refer to the publisher's version if you intend to cite from the work. See Guidance on citing.

Published version at: http://dx.doi.org/10.1016/j.cplett.2015.10.047

To link to this article DOI: http://dx.doi.org/10.1016/j.cplett.2015.10.047

Publisher: Elsevier

All outputs in CentAUR are protected by Intellectual Property Rights law, including copyright law. Copyright and IPR is retained by the creators or other copyright holders. Terms and conditions for use of this material are defined in the End User Agreement.

www.reading.ac.uk/centaur 
Central Archive at the University of Reading

Reading's research outputs online 


\title{
Morphology of polymer networks formed in the chiral and non chiral phases of an anti-ferroelectric liquid crystal
}

Upindranath Singh $^{\mathrm{a}}$, Mathew Spink ${ }^{\mathrm{b}}$, Frederic Davis ${ }^{\mathrm{b}}$ and Geoffrey Mitchell ${ }^{\mathrm{c}}$

a. Physics Department, University of the West Indies, P.O. Box 64, Bridgetown, BARBADOS

b. Centre for Advanced Microscopy (CFAM), University of Reading, Reading RG6 6AD, UK

c. Centro Empresarial da Marinha Grande Rua de Portugal-Zona Industrial 2430-028

Marinha Grande-PORTUGAL

Email: upindranath.singh@ cavehill.uwi.edu: Phone \#246 - 417- 4376

\begin{abstract}
We introduced photo-polymer networks into the various liquid crystalline phases of the antiferroelectric liquid crystal AS612 and studied the effects of these networks by measuring the temperature dependence of the Bragg wavelengths selectively reflected. After polymerization, the decrease in Bragg wavelengths with respect to the original values is consistent with a shorter helical pitch due to polymer network shrinkage. Also, by removing the liquid crystalline material, we are able to image the residual polymer network using scanning electron microscopy and polarized light microscopy. The polymer strands are a few microns thick and the networks show both chiral and nonchiral features.
\end{abstract}

\section{KEYWORDS}

Polymer networks

Chiral smectic phases

Selective Bragg Reflection

Phase Transitions

Scanning Electron Microscopy 


\section{Introduction}

Owing to their compact size, low voltage demands and low power consumption, liquid crystal displays (LCDs) are expected to dominate the portable market [1]. However, such devices lack ruggedness as the liquid crystalline material can be easily deformed by weak external forces. Polymer networks which basically stabilize a desired liquid crystal director configuration protect electro-optic devices from mechanical shock [2]. Polymer-stabilized- liquid crystals (PSLCs) are blends in which a small amount ( 3-5 wt. \%) of cross-linked polymer is dispersed within a liquid crystal medium [3-8]. Usually, a photo-initiator and a monomer are required to introduce cross-linking within a liquid crystal-polymer blend [9]. However, some polymers contain photoreactive components that are sensitive to ultra violet radiation and do not require a photoinitiator. Poly (vinyl cinnamate) for example, undergoes a random cross-linking photo-addition reaction when exposed to ultra violet radiation. The advantage of using one procedure over the other has not been investigated.

Of the materials presently used in displays, only ferroelectrics and antiferroelectrics offer potential for switching times in the sub-microsecond range [10]. However, antiferroelectric liquid crystals (AFLCs) show larger switching angles of the optical axis than ferroelectric liquid crystals FLCs which is essential in achieving higher contrast ratios [11]. In AFLCs-based devices, the surface-stabilized Sm-C*A phase serves as the dark state while the field-induced SmC* phase forms the bright state [12]. Recent developments in AFLCs-type displays involve the use of high tilt materials to achieve a completely dark state [13]. Such materials termed orthoconic antiferroelectric liquid crystals (OAFLCs) are characterized by saturation tilt angles of $\sim 45^{\circ}$.

In addition to enhancing mechanical integrity, low density polymer networks improve the alignment of AFLCs and reduce the switching times [11, 14-15]. However, network stabilization is antagonistic towards liquid crystalline order and a delicate balance must be maintained in order to optimize the performance of polymer stabilized devices. A previous study revealed that for polymer concentrations of 3\%, the phase stability of the Sm-C* phase of AS661 was not significantly affected, but, the blends retain enough order to Bragg reflect visible light [16]. Motivated by these results, we studied samples of AS612 (see Fig. 1a) that were doped with $3 \%$ of the photo-polymer and then cross-linked at temperatures corresponding to the 
various liquid crystalline phases of AS612. A photo-polymer network aligns itself roughly parallel to the local director orientation of the mesophase and hence, serves as a template of the liquid crystalline order [17, 18]. After cross-linking, the liquid crystal can be dissolved and the residual network can be studied as a representation of liquid crystalline order without having to resort to temperature control. The aim of this study is to prepare and image these networks and gather direct evidence of how liquid crystalline order influence network topology and vice versa.

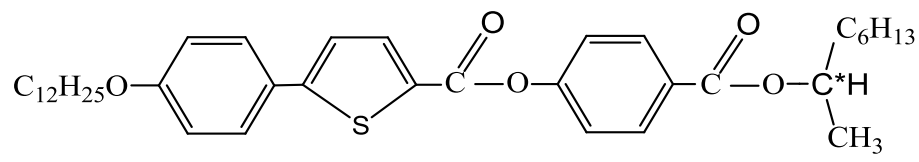

Fig.1a. Chemical structure of AS 612.

\section{Experimental}

The antiferroelectric crystal AS612 was purchased from Kingston Chemicals and used as obtained. The blend was prepared by mixing the monomer BAB6, the photoiniatator (Irgacure 651) and AS612. The chemical structure and the associated transitions of BAB6 (from DSC and POM) are shown in Fig 1b. The ratio of BAB6 to Irgacure 651 was 4:1. To ensure a uniform and accurate composition, the monomer-photoiniatator blend was dissolved in a minimum amount of dry dichloromethane (DCM) and the desired volumes then added to AS612 to prepare the $3 \%$ by weight polymer blend. The solution was then dried in an inert atmosphere at $60{ }^{\circ} \mathrm{C}$. Homeotropically aligned samples were heated into the isotropic phase, cooled slowly into the desired phase of AS612 and then cross-linked. Homeotropic alignment was achieved by using aqueous cetyl-trimethyl-ammonium bromide (CETAB) and polymer networks were introduced by using unpolarized UV radiation $\left(10 \mathrm{~mW} \mathrm{~cm}^{-2}\right)$ which has a wavelength of $365 \mathrm{~nm}$. The network was recovered by dissolving the liquid crystal component in DCM. 


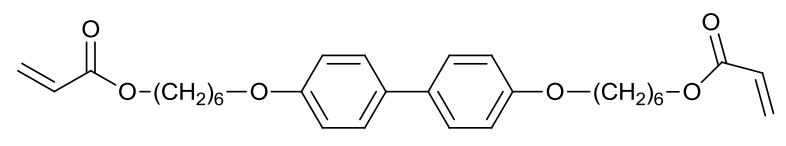

$$
\mathrm{K} \stackrel{82.21 \mathrm{C}}{\longrightarrow} \mathrm{N} \stackrel{125.72 \mathrm{C}}{\longrightarrow} \text { Iso }
$$

Fig. 1b. Chemical structure and phase transitions of BAB6.

\section{Results and Discussions}

It is useful to report on the phases of pure AS612 before discussing polymer stabilization. The phase sequence (cooling mode) shown below is deduced from combined polarized light microscopy and Bragg scattering studies [19].

Iso $\stackrel{97.53}{\longrightarrow}$ SmA $\stackrel{93.47}{\longrightarrow}$ SmC $^{*} \stackrel{82.60}{\longrightarrow}$ SmC $^{*}$ FI1 $\stackrel{80.21}{\longrightarrow}$ SmC $^{*} \stackrel{36.00}{\longrightarrow}$ Cry.

The Bragg wavelengths selectively reflected by pure AS612 is shown in Fig. 2 and the corresponding polarized light microscopic images are shown in Fig. 3. In general, Bragg reflections in the visible region correspond to half-pitch and full-pitch reflections from the Sm$\mathrm{C}^{*}$ phase and half-pitch reflections in the $\mathrm{SmC}^{*}{ }_{\mathrm{A}}$ phase [20]. However, only half-pitch reflections were detected for AS612. The Sm-C*F1 phase which does not reflect visible light is sandwiched between two reflecting phases and hence, easily identified. Bragg reflections for the Sm-C* ${ }^{*}$ phase could only be detected by our equipment for temperatures above $\sim 50{ }^{\circ} \mathrm{C}$. 


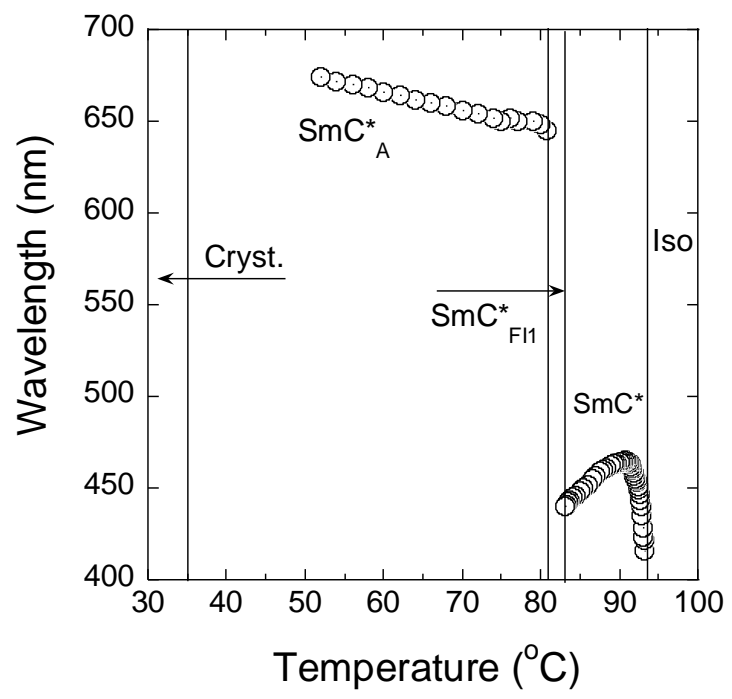

Fig. 2. The Bragg wavelengths selectively from pure AS612 (cooling mode).
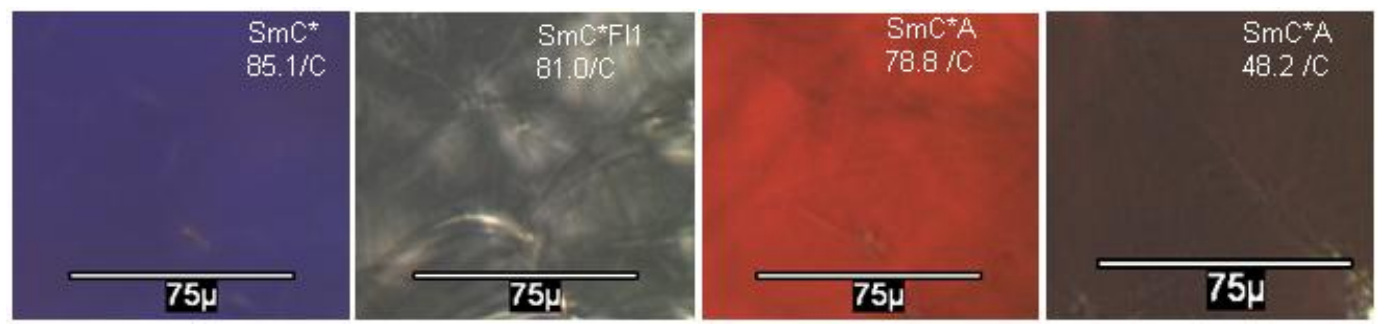

Fig. 3. Bragg wavelengths selectively reflected by the chiral phases of AS612. The wavelengths increase with decreasing temperature. However, the $\mathrm{SmC}^{*}$ FII phase does not reflect visible light.

A polarized light microscopic image of a blend (3\% polymer) which was cross-linked while the sample was in the $\mathrm{SmC}^{*}$ F1 phase appears in Fig. 4. The lines (not present in the pure LC sample) represent polymer strands. The cross-linked sample is temperature insensitive and it retains its features even if heated from room temperature up to $200{ }^{\circ} \mathrm{C}$. This suggests that the helical pitch is fixed and as expected, there are no Bragg reflections. The pitch of the SmC* ${ }^{*}$ FI determined from the separation of the disclination lines in the micro-photo (Fig. 4) is $4.1 \pm 0.3 \mu \mathrm{m}$ and the polymer strands are $\sim 2.0 \pm 0.5 \mu \mathrm{m}$ thick. These values represent the average of 100 measurements. For comparison, the pitch of the $\mathrm{SmC}^{*} \mathrm{Fl}$ deduced from direct observations of disclination lines in the antiferroelectric liquid crystal 10OTBBB1M7 varies 
from $\sim 2-3 \mu \mathrm{m}$ over its temperature range [21]. Owing to its temperature insensitivity, this blend offers potential for applications as high-temperature IR neutral density filters.

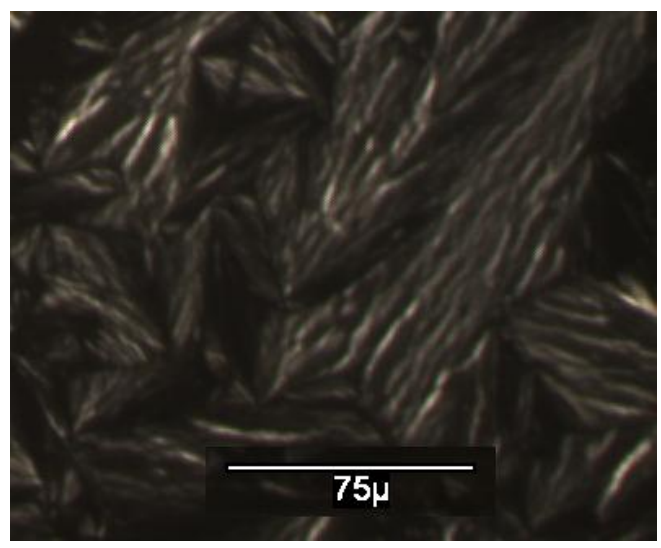

Fig. 4. Polarized optical microscopic image of a $3 \%$ polymer blend that was homeotropically aligned prior to cross-linking. The sample was kept in the SmC* FI1 phase at $75^{\circ} \mathrm{C}$ and irradiated with unpolarized UV light $\left(10 \mathrm{~mW} \mathrm{~cm}^{-2}\right.$ and $\left.365 \mathrm{~nm}\right)$ for 15 minutes.

If a highly chiral liquid crystal is doped with a non-chiral material, the pitch generally increases owing to reduced chiral interactions. However, the opposite effect is observed if a photo-polymer network is introduced into a highly chiral mesophase; the pitch of this phase decreases owing to radiation-induced network shrinkage. This effect has been observed in the SmC* phase of a FLC [22]. This study extends this observation by measuring how Bragg peaks are affected if cross-linking is performed in the non-chiral (SmA) and chiral phases (SmC* and SmC*A). The Bragg wavelengths reflected by the $\mathrm{SmC}^{*}$ phase for samples that were crosslinked in all three phases are captured in Fig. 5. These wavelengths when compared to pure AS612 (Fig. 2) are shifted towards shorter wavelengths. However, the magnitude of this wavelength shift appears to be inversely related to the pitch in which the cross-linking was performed (shift is greatest for the $\mathrm{SmC}^{*}$ phases and least for the SmA phase). In addition, the expected decrease in SmA-SmC* transition temperatures and the reduced stability of the SmC* phase are obvious in Fig. 5. 


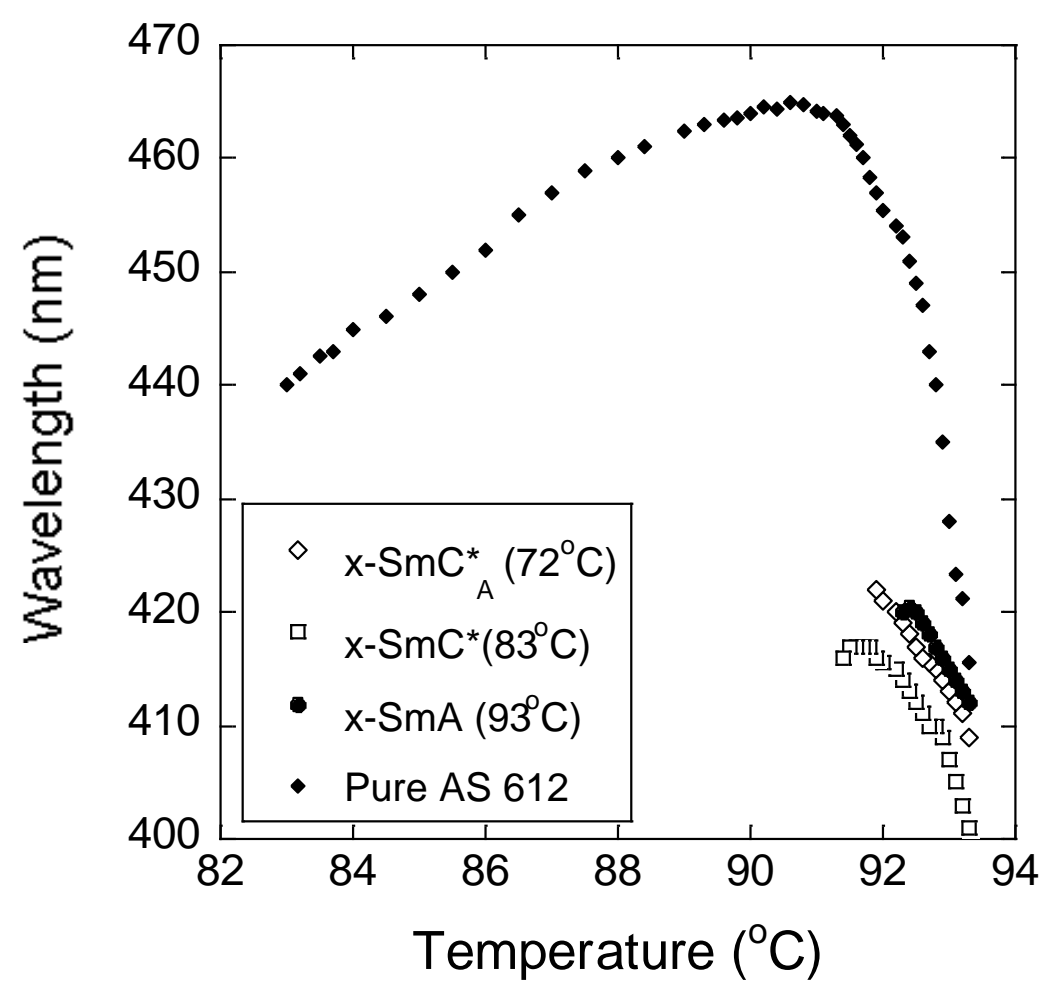

Fig. 5. (a) Temperature dependence of Bragg wavelengths reflected by the SmC* phase for the $3 \%$ polymer blends which were crossed-linked $(15 \mathrm{~min})$ at different temperatures: $\operatorname{SmA}\left(93{ }^{\circ} \mathrm{C}\right)$, $\mathrm{SmC}^{*}\left(83^{\circ} \mathrm{C}\right)$ and $\mathrm{SmC}^{*} \mathrm{~A}\left(72^{\circ} \mathrm{C}\right)$ phases. For comparison, the pure material is also included.

The samples were cooled into $\mathrm{SmC}^{*}$ A phase and the Bragg wavelengths then measured. Selective reflections were detected only for the two samples that were cross-linked in the SmA and $\mathrm{SmC}^{*}$ A phases (see Fig. 6). The reflected wavelengths in both cases (Fig. 6) are temperature insensitive varying by $\sim 2.0 \mathrm{~K}$ over a $20 \mathrm{~K}$ interval. The sample that was cross-linked in the SmC* phase did not yield Bragg reflections when it was cooled into the $\mathrm{SmC}^{*}$ a phase. A polymer network will tend to stabilize a prepared helical pitch which is unlikely to favour the formation of a phase with a longer helical pitch. Hence, since the pitch of the $\mathrm{SmC}_{\mathrm{A}}$ * phases is greater than that of the $\mathrm{SmC}$ phase, cross-linking in the $\mathrm{SmC}_{\mathrm{A}}$ * leads to the formation of the SmC* phase but the inverse has not been observed. 


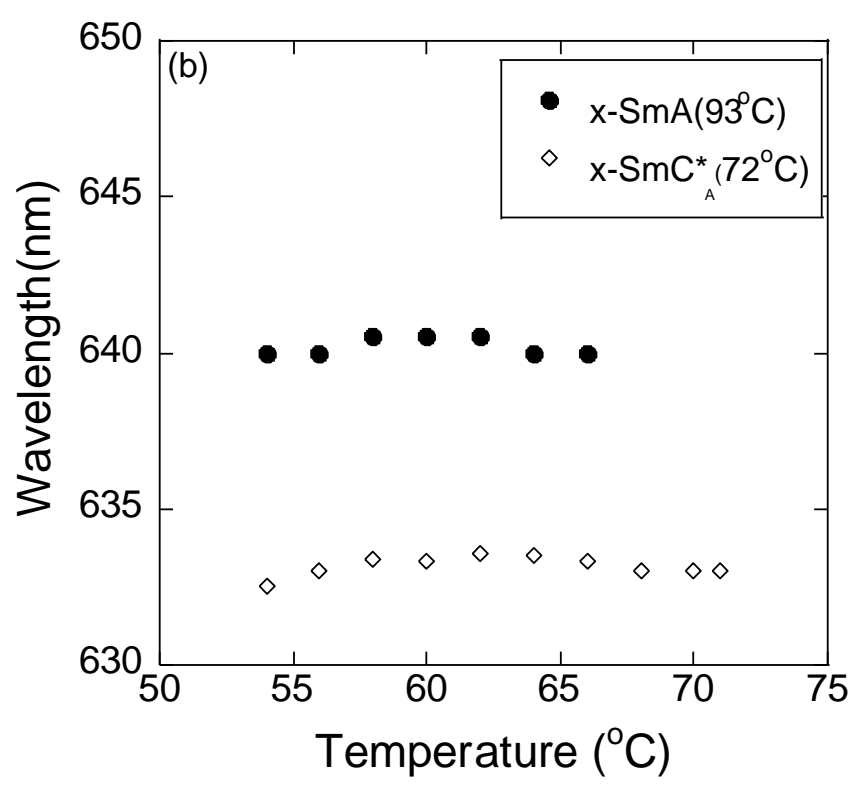

Fig. 6. Bragg peaks detected in the $\mathrm{SmC}^{*}$ A phase for samples that were cross-linked in the SmA $\left(93{ }^{\circ} \mathrm{C}\right)$ and $\mathrm{SmC}^{*}{ }_{\mathrm{A}}\left(72{ }^{\circ} \mathrm{C}\right)$ phases. No peaks were detected for the sample that was crosslinked in the $\mathrm{SmC}^{*}$ phase.

We employed the FEI 600F Quanta Electron Microscope (University of Reading) to image the residual networks of the three samples that are the focus of this study. The samples were gold coated to enhance the SEM images. Figure 7 shows the residual network images for a sample that was cross-linked in the SmA phase at $93{ }^{\circ} \mathrm{C}$. The $1 \mathrm{~K}$ magnified image may be interpreted as surface-induced $S=+1 / 2$ and $S=-1 / 2$ wedge disclination lines that have merged in some areas. These defects are of similar energies and the geometry of these wedge disclinations allow for parallel lines [23]. The $20 \mathrm{~K}$ image shows a magnified view of these defect lines which appear as a series of nearly parallel lines $\sim 1.5 \mu \mathrm{m}$ apart. 

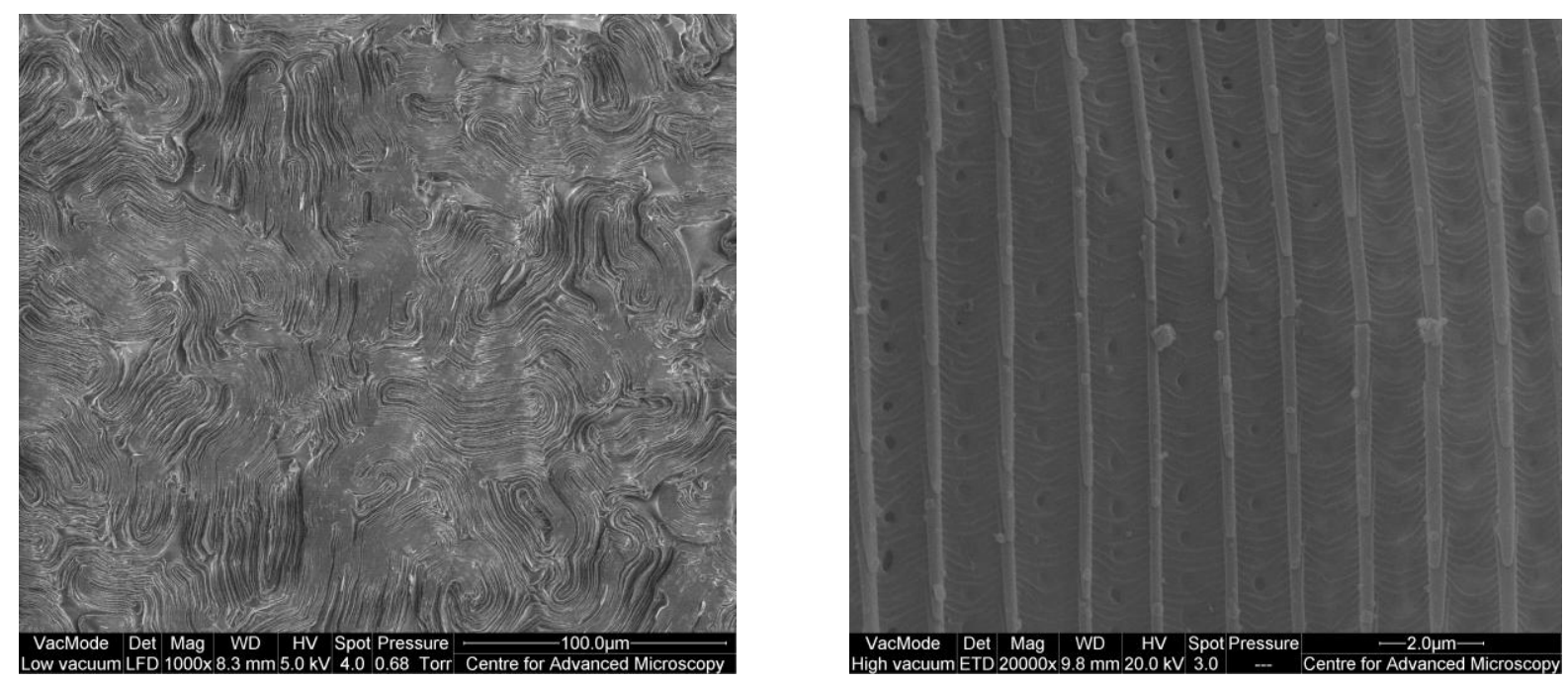

Fig.7. SEM image of the network generated by an aligned sample of 3\% polymer blend that was cross-linked in the SmA phase at $93{ }^{\circ} \mathrm{C}$. The magnifications are $1 \mathrm{~K}$ (left image) and $20 \mathrm{~K}$ (right image).

The residual network after cross-linking in the $\mathrm{SmC}^{*}$ is shown in Fig. 8. This scan, unlike that of Fig. 7 shows the effects of crosslinking in a chiral phase. The low magnification scans appear to be similar defect-type structures since both phases are fluid smectics with a sinusoidal variation in the direction along the smectic layer normal. However, the magnified images show the expected chiral and nonchiral features of the accompanying phases. 

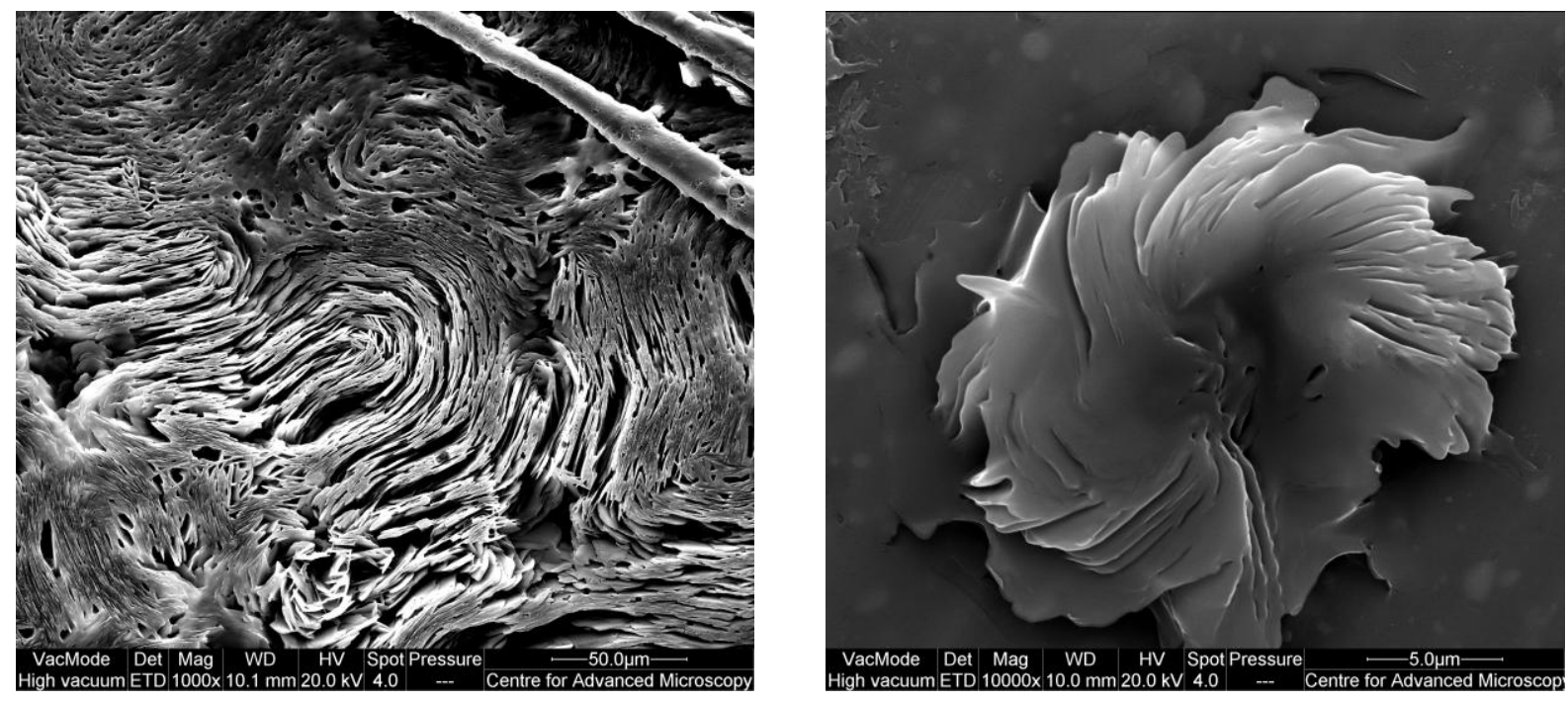

Fig. 8. SEM images generated by an aligned sample of a $3 \%$ polymer blend that was crossedlinked in the $\mathrm{SmC}^{*}$ phase at $83^{\circ} \mathrm{C}$. The magnifications are $1 \mathrm{~K}$ (left image) and $10 \mathrm{~K}$ (right image). The twist associated with chiral phases is visible in both images.

\section{Conclusion}

We have introduced photo-polymer networks into the chiral and non-chiral phases of the AFLC (AS612) liquid crystal and explored the effects of these networks on some of the optical and thermal properties of the liquid crystalline material. Prior to cross-linking, the monomer and photo-initiator act merely as impurities. These dopants reduce chiral interactions which effectively increase the helical pitch of the chiral phases. On the other hand, the shift to shorter wavelengths of the Bragg reflection wavelengths in the cross-linked samples indicates a radiation-induced pitch reduction. During the cross-linking process, the helical pitch decreases in response to the shrinking network. The recovered networks show the local director orientation of the phases in which the cross-linking was performed. The twist associated with the SmC* phase is quite evident in Fig. 8. 


\section{References}

[1] S.T. Wu and D.-K. Yang, Reflective Liquid Crystal Displays (John Wiley \&Sons, New York, 2004).

[2] D. Broer, K. Gossink and R.A.M. Hikmet, Angew. Makromol. Chem. 183, 45 (1990).

[3] G.P. Crawford and S. Zumer, Liquid Crystals in Complex Geometeries formed by Polymer and Porous Networks (Taylor and Francis, 1996).

[4] Y.K. Fung, D.-K. Yang, S. Ying, L.-C. Chien, S. Zumer and J.W. Doane, Liq. Cryst. 19, $797,1995$.

[5] R.A.M. Hikmet, Liq. Cryst. 9, 405, 1991.

[6] H. Kikuchi, M. Yokota, Y. Hisakado, H. Yang and T. Kajiyama, Nature Mater. 1, 6469 (2002).

[7] H. J. Coles and M. N. Pivnenko, Nature 436, 997 (2005).

[8] I. Dierking, Materials 7, 3568 (2014).

[9] C.V. Rajaram, S.D. Hudson and L.C. Chien, Chem. Mater. 8, 2451 (1996).

[10] A. Jákli and A. Saupe, One-and two-Dimensional Fluids (Taylor and Francis, 2006).

[11] B. Atorf, A. Hoischen, M. B. Ros, N. Gimeno, C. Tschierske, G. Dantlgraber and H. Kitzerow, Appl. Phys. Lett. 100, 223301 (2012).

[12] N. Clark and S.T. Lagerwall, Appl. Phys. Lett. 36, 899 (1980).

[13] S.T. Lagerwall, A. Dahlgren, P. Jagemalm, P. Rudquist, K. D’Have, H. Pauwels, R. Dabrowski and W. Drzewiński, Adv. Funct. Mater., 11, 87 (2001).

[14] R. Dabrowski, J. Gasowska, J. M. Otón, W. Piecek, J. Przedmojski and M. Tykarska, Displays, 25, 9 (2004).

[15] M. Shikada, Y. Tanaka, J. Xu, K. Furuichi, H. Hasebe, H. Takatsu and S. Kobayashi, Jap. J. Appl. Phys., 40, 5008 (2001).

[16] U. Singh and S. Bradshaw, Phys. Rev. E 87, 042507 (2013).

[17] A.Y.-G. Fuh, M.-S. Tsai and C.-Y. Huang, Jpn. J. Appl. Phys. 35, 3960 (1996). 
[18] I. Dierking, L.L. Kosbar, A. Afzali-Ardakani, A.C. Lowe and G.A. Held, J. Appl. Phys. 81, 3007 (1997).

[19] U. Singh, H.F. Gleeson, J.W. Goodby and M. Hird, Ferroelectrics, 277, 153 (2002).

[20] R.B. Meyer, L. Liebert, L. Strzelecki and P. Keller, J. Phys. (Paris), Lett. 36, L169 (1975).

[21] I. Muševič and M. Škarabot, Phys. Rev. E, 64, 051706 (2001).

[22] U. Singh, Phys. Rev. E 83, 061707 (2011).

[23] M. Kléman, Rep. Prog. Phys. 52, 555, (1989). 